\title{
A Nonlinear Fatigue Damage Model Based on Equivalent Transformation of Stress
}

\author{
Lu Zhang $\mathbb{D}^{1,2}$ Jie Jin, ${ }^{1,2}$ Wei Zhou, ${ }^{1,2}$ Wen-Liang Li, ${ }^{1,2}$ and Meng Qiao ${ }^{3}$ \\ ${ }^{1}$ Key Laboratory of Operation Safety Technology on Transport Vehicles, Ministry of Transport, Beijing 100088, China \\ ${ }^{2}$ Research Institute of Highway Ministry of Transport, Ministry of Transport, Beijing 100088, China \\ ${ }^{3}$ Sinomach TDI International Engineer Co. Ltd, Beijing 100083, China
}

Correspondence should be addressed to Lu Zhang; luzh_cau@126.com

Received 6 January 2021; Revised 10 September 2021; Accepted 15 October 2021; Published 9 November 2021

Academic Editor: Yaowen Yang

Copyright (C $2021 \mathrm{Lu}$ Zhang et al. This is an open access article distributed under the Creative Commons Attribution License, which permits unrestricted use, distribution, and reproduction in any medium, provided the original work is properly cited.

It is rather difficult for engineers to apply many of the fatigue damage models for requiring a knee point, material-dependent coefficient, or extensive testing, and some of them are only validated by a fatigue test of two-stage loading rather than higher-stage loading. In this paper, we propose a new model of fatigue cumulative damage in variable amplitude loading, which just requires the information of the S-N curve determined from the fatigue experiment. Specifically, the proposed model defines a stress equivalent transformation way to translate the damage of one stress to another stress through simple calculation. Experimental data of fatigue including two-, three-, and four-block loading verify the superiority of the proposed model by comparing it with the Miner model and Manson model. The results show that the proposed model can be generalized to any type of loading and presents a better prediction. Therefore, the advantage of the proposed model can be easily used by an engineer.

\section{Introduction}

Fatigue fracture plays an important role in the failure of mechanical components, which accounts for $80 \%-90 \%$ of the failure probability [1]. Miner [2] first proposed a cumulative damage criterion that could explain the fatigue failure mechanism, which is still extensively applied in engineering owing to its simplicity. However, many fatigue experiments indicated that the Miner criterion would have a significant deviation in predicting the cumulative fatigue damage when the sequence of fatigue loading is changed [3]. Therefore, relevant researchers have discussed the evolution process of fatigue cumulative damage from different perspectives.

Considering the linear damage at different stages, Manson et al. [4] proposed a double linear damage rule by setting the intersection point of two lines as a knee point. Then, Manson et al. [5] improved his model and put forward a double damage curve approach. Meanwhile, some researchers have developed nonlinear models of fatigue cumulative damage. Subramanyan [6] and Hashin et al. [7] proposed the power law rule by considering a knee point in the $\mathrm{S}-\mathrm{N}$ curve to predict the remaining damage, which needs the endurance limit of material. Manson et al. [5] derived the power law rule, which is a simple model relying only on the S-N curve. Shang et al. [8] proposed a new nonlinear model of fatigue cumulative damage based on the evolution law of the material ductility during fatigue damage. Yao et al. [9-11] constructed some nonlinear models according to the equivalent principle of between the strength degradation or stiffness degradation and fatigue damage. Djebli et al. [12] proposed a nonlinear fatigue damage accumulation model relying on the application of energy parameters. Mesmacque et al. [13] defined a damage stress to propose a new damage indicator according to sequential law in multiaxial loading, and the ultimate stress of material should be joined in the model. Despite extensive works on this area, nevertheless, many of these models require a knee point, material-dependent coefficient, or extensive testing, and some of them are only validated by a fatigue test of two-stage loading rather than higher-stage loading. 
Therefore, it is difficult to apply them to fatigue damage prediction because test data may not be available to an engineer.

Considering the above-mentioned situation, the present work aims to apply a new fatigue damage model in a simple way under variable amplitude loading. In Section 2 , a new nonlinear fatigue damage model is proposed based on the correction and equivalent transformation of stress progression. The proposed model relies only on the S-N curve and does not need other fixed points or other material parameters, while also being applicable for fatigue analysis engineers. Then, the proposed model is applied to fatigue tests of two-, three-, and four-block loading. We compare the prediction results of the Miner model, Manson model, and the proposed model with the experimental results under different loading conditions, respectively. Finally, the effectiveness of the proposed model is verified.

\section{Model Details}

In this section, we propose a new nonlinear fatigue damage model. The proposed model only relies on equivalent transformation of stress, which just requires the information of the S-N curve. The proposed model takes the interactions between loading sequences into account.

2.1. Miner and Manson Model. The fatigue life of the material under the action of stress amplitude $S_{i}$ is $N_{i}$, and the damage in a cycle action is as follows:

$$
D_{i}=\frac{1}{N_{i}}
$$

Let us define the sum of the damage $D_{i}$ of all extracted cycles as the cumulative fatigue damage. Let us suppose the stress $S_{1}, S_{2} \cdots S_{k}$ of the material is subjected to $n_{1}, n_{2} \cdots n_{k}$, and the cumulative fatigue damage is as follows:

$$
D=\sum_{i=1}^{k} \frac{n_{i}}{N_{i}}
$$

Fatigue fracture occurs when $D=1$.

Manson [5] proposed a power law accumulation rule based on crack propagation for multilevel loading:

$$
D=\left[\left[\left[\left(\frac{n_{1}}{N_{1}}\right)^{\alpha_{1,2}}+\frac{n_{2}}{N_{2}}\right]^{\alpha_{2,3}}+\frac{n_{3}}{N_{3}}\right]^{\alpha_{3,4}} \cdots+\frac{n_{i-1}}{N_{i}}\right]^{\alpha_{i-1, i}}+\frac{n_{i}}{N_{i}},
$$

where $\alpha_{i-1, i}=\left(N_{i-1} / N_{i}\right)^{0.4}$.

2.2. Proposed Damage Model. The Basquin [14] model can be applied to establish the relationship between stress amplitude and fatigue life curves of materials, which is described by the following relation:

$$
\sigma=a N^{b}
$$

where $a$ and $b$ can be determined by fatigue experimental data.

2.2.1. Two-Block Loading. The process of equivalent transformation relationship under two-block loading is shown in Figure 1. The assumptions of the model are as follows:

(1) During the loading process, each cycle loses a certain effective life component of the sample

(2) The fatigue damage of the sample is directly proportional to the work absorbed, and the work is directly proportional to the ratio of the number of stress cycles and the number of failure cycles under the stress value

(3) The total amount of damage is a constant

(4) The stress below the fatigue limit no longer causes damage

(5) Damage is related to the action sequence of loads

(6) When the sum of all damage components generated by each cyclic stress is 1 , the specimen will be destroyed

We can see from Figure 1 the corresponding stress amplitude $S_{1 r}$ under the remaining life $N_{1}-n_{1}$. Therefore, the relation is as follows:

$$
\begin{gathered}
N_{1 r}=N_{1}-n_{1}, \\
S_{1 r}=a N_{1 r}^{b} .
\end{gathered}
$$

In this case, $\Delta S_{1}$ is the difference between $S_{1 r}$ and $S_{1}$; that is,

$$
\Delta S_{1}=S_{1 r}-S_{1}
$$

Let us define a stress equivalent transformation way to translate the first stress $S_{1}$ to the second stress $S_{2}$, and the expression is as follows:

$$
S_{2 e}=S_{2}+\Delta S_{1} \frac{S_{1}}{S_{2}}
$$

We can obtain the corresponding life $N_{2 e}$ under the stress amplitude $S_{2 e}$ in the S-N curve:

$$
N_{2 e}=e^{b \times \log \left(S_{2 e} / a\right)} .
$$

If it is just two-block loading, the remaining cycles of stress $S_{2}$ is

$$
N_{2 r}=N_{2 e} \text {. }
$$

Therefore, the equivalent damage of stress $S_{1}$ subjected to $n_{1}$ cycle transform to the second stress $S_{2}$ is

$$
d_{12 e}=1-\frac{N_{2 e}}{N_{2}} \text {. }
$$

The cumulative damage of two-block loading is

$$
D_{2}=d_{12 e}+\frac{n_{2}}{N_{2}}
$$




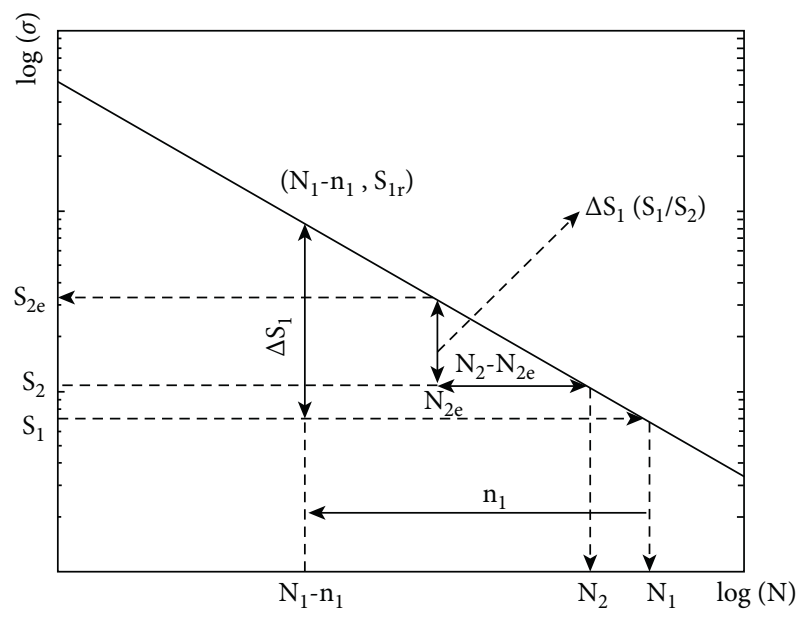

Figure 1: Two-block fatigue loading process.

2.2.2. Three-Block Loading. Let us translate the damage from two blocks to three blocks, and the calculation steps are as follows:

$$
\begin{aligned}
& N_{2 r}=N_{2}-N_{2} D_{2}, \\
& S_{2 r}=a N_{2 r}^{b}, \\
& \Delta S_{2}=S_{2 r}-S_{2}, \\
& S_{3 e}=S_{3}+\Delta S_{2} \frac{S_{2}}{S_{3}} \\
& N_{3 e}=e^{b \times \log \left(S_{3 e} / a\right)} \\
& d_{23 e}=1-\frac{N_{3 e}}{N_{3}}, \\
& D_{3}=d_{23 e}+\frac{n_{3}}{N_{3}} .
\end{aligned}
$$

We follow the same procedure until fatigue fracture.

2.2.3. The Remaining Life and Damage in Multiblock Loading. Similarly, we get the remaining life and damage in multiblock loading:

$$
\begin{gathered}
N_{i r}=N_{i e}, \\
d_{i r}=\frac{N_{i e}}{N_{i}},
\end{gathered}
$$

where $N_{i r}$ is the remaining life at stress level $i ; d_{i r}$ is the remaining damage at stress level $i$.

\section{Experimental Verifications}

We apply the experimental data of two-, three-, and fourblock loading to validate the Miner model, Manson model, and the proposed model by calculating the remaining damage.

\subsection{Two-Block Loading}

3.1.1. Al-2024. The material studied by Pavlou [15] is the aluminium alloy Al-2024. The material coefficient is $a=$ 5189.39 and $b=-0.273$. Fatigue life under different stress amplitude is shown in Table 1 . The remaining damage of the Miner, Manson, and the proposed model is predicted and compared in experiments, as shown in Table 2.

3.1.2. GS61. Similarly, we apply the plane bending test data spheroïdal graphite cast-iron (GS61) [16] material to predict the fatigue damage. Fatigue life under different stress amplitudes is shown in Table 3. The remaining damage of the Miner, Manson, and the proposed model is predicted and compared with experimental results, as illustrated in Table 4.

3.1.3. 30CrMnSiA. We then apply the experimental data of 30CrMnSiA [17] material under two-block loading. Fatigue life under different stress amplitudes is shown in Table 5. The remaining damage of the Miner, Manson, and proposed model is predicted and compared with experimental results in Table 6.

Through the comparative analysis of two-block loading fatigue experimental data of the three kinds of material, we can see that the proposed model can significantly improve the prediction accuracy of fatigue life compared with the Miner.

3.2. Three-Block Loading. The fatigue test cycles of LY12CZ [18] material under different loading amplitudes are shown in Table 7. The three-block loading sequence includes lowhigh loading, low-high-low loading, high-low loading, and high-low-high loading, respectively. The remaining damage of the Miner, Manson, and the proposed model is predicted and compared in Table 8.

Therefore, we can see that the deviation of the Miner model and Manson model is larger than that of the proposed model in three-block loading. The Manson model tends to be aggressive or conservative when the changes between loading amplitude are large.

3.3. Four-Block Loading. We choose Mesmacque's [13] experimental data of four-block loading to predict the fatigue life and damage. The fatigue life and applied cycles under different loading conditions are shown in Table 9. The parameters of Basquin's function are $a=856$ and $b=-0.08735$.

The loading sequence is shown in Figure 2. The cumulative fatigue life and damage of the Miner, Manson, and proposed model is predicted and compared with experimental results, shown in Table 10 .

\section{Discussion}

4.1. Characteristics of the Proposed Model. The characteristics of the proposed model in fatigue damage prediction under two-block loading are shown in Figure 3. 
TABle 1: Fatigue life under different stress amplitudes.

Stress amplitude/MPa

Life/cycle

150

430,000 200 150,000

TABle 2: The comparison of the experimental results, Miner, Manson, and proposed model for Al-2024 material under two-block loading.

\begin{tabular}{|c|c|c|c|c|c|c|c|c|c|c|}
\hline \multirow{2}{*}{ Stress amplitude } & \multicolumn{3}{|c|}{ Experimental } & \multicolumn{3}{|c|}{ Miner } & \multicolumn{2}{|c|}{ Manson } & \multicolumn{2}{|c|}{ Proposed model } \\
\hline & $\mathrm{n} 1$ & $\mathrm{~d} 1$ & Result & $\mathrm{d} 2$ & $\mathrm{~d} 2$ & Dev/\% & $\mathrm{d} 2$ & Dev/\% & $\mathrm{d} 2$ & Dev/\% \\
\hline \multirow{3}{*}{$150-200$} & 86000 & 0.2 & 144,500 & 0.96 & 0.80 & 16.8 & 0.91 & 5.10 & 0.88 & 8.22 \\
\hline & 172000 & 0.4 & 133,500 & 0.89 & 0.60 & 32.5 & 0.75 & 15.45 & 0.74 & 15.73 \\
\hline & 258000 & 0.6 & 81,700 & 0.54 & 0.40 & 26.5 & 0.54 & 0.20 & 0.58 & 7.41 \\
\hline \multirow{3}{*}{$200-150$} & 30000 & 0.2 & 228,700 & 0.67 & 0.80 & 50.5 & 0.65 & 5.12 & 0.68 & 0.75 \\
\hline & 60000 & 0.4 & 101,050 & 0.24 & 0.60 & 155 & 0.45 & 90.83 & 0.42 & 74.79 \\
\hline & 90000 & 0.6 & 76,050 & 0.18 & 0.40 & 126 & 0.28 & 42.33 & 0.22 & 23.72 \\
\hline
\end{tabular}

TABLE 3: Fatigue life under different stress amplitudes.

\begin{tabular}{lccc}
\hline Level & S1 & S2 & S3 \\
\hline Stress amplitude $(\mathrm{MPa})$ & 303 & 320 & 352 \\
Life/cycle & 588,200 & 322,580 & 112,867 \\
\hline
\end{tabular}

TABLE 4: The comparison of the experimental results, Miner, Manson, and proposed model for GS61 material under two-block loading.

\begin{tabular}{|c|c|c|c|c|c|c|c|c|c|c|}
\hline \multirow[b]{2}{*}{ Loading sequence } & \multirow[b]{2}{*}{ Stress amplitude } & \multicolumn{3}{|c|}{ Experimental } & \multicolumn{2}{|c|}{ Miner } & \multicolumn{2}{|c|}{ Manson } & \multicolumn{2}{|c|}{ Proposed model } \\
\hline & & $\mathrm{n} 1$ & d1 & $\mathrm{d} 2$ & $\mathrm{~d} 2$ & Dev/\% & $\mathrm{d} 2$ & Dev/\% & $\mathrm{d} 2$ & Dev/\% \\
\hline \multirow{2}{*}{ Low-high } & $320-352$ & 110,000 & 0.341 & 0.734 & 0.659 & 10.22 & 0.805 & 9.74 & 0.708 & 3.55 \\
\hline & $303-352$ & 160,000 & 0.272 & 1.03 & 0.728 & 29.32 & 0.920 & 10.73 & 0.790 & 23.33 \\
\hline \multirow{2}{*}{ High-low } & $352-320$ & 50,000 & 0.443 & 0.405 & 0.557 & 37.53 & 0.415 & 2.49 & 0.498 & 23.04 \\
\hline & $352-303$ & 50,000 & 0.443 & 0.349 & 0.557 & 59.60 & 0.344 & 1.40 & 0.461 & 32.19 \\
\hline
\end{tabular}

TABle 5: Fatigue life under different loading amplitudes.

\begin{tabular}{lcc}
\hline Stress amplitude/MPa & 482 & 586 \\
\hline Life/cycle & 55,757 & 7186 \\
\hline
\end{tabular}

TABLE 6: The comparison of the experimental results, Miner, Manson, and proposed model for 30CrMnSiA material under two-block loading.

\begin{tabular}{|c|c|c|c|c|c|c|c|c|c|c|}
\hline \multirow{2}{*}{ Stress amplitude } & \multicolumn{4}{|c|}{ Experimental } & \multicolumn{2}{|c|}{ Miner } & \multicolumn{2}{|c|}{ Manson } & \multicolumn{2}{|c|}{ Proposed model } \\
\hline & $\mathrm{n} 1$ & $\mathrm{~d} 1$ & Result & $\mathrm{d} 2$ & $\mathrm{~d} 2$ & Dev/\% & $\mathrm{d} 2$ & Dev/\% & $\mathrm{d} 2$ & Dev/\% \\
\hline \multirow{4}{*}{$586-482$} & 1200 & 0.167 & 36911 & 0.662 & 0.833 & 25.83 & 0.546 & 17.52 & 0.764 & 15.41 \\
\hline & 1800 & 0.208 & 32451 & 0.582 & 0.792 & 36.08 & 0.499 & 14.26 & 0.710 & 21.99 \\
\hline & 3000 & 0.417 & 16002 & 0.287 & 0.583 & 103.1 & 0.320 & 11.50 & 0.455 & 58.54 \\
\hline & 5000 & 0.694 & 6970 & 0.125 & 0.306 & 144.8 & 0.149 & 19.20 & 0.182 & 45.60 \\
\hline \multirow{5}{*}{$482-586$} & 13,000 & 0.233 & 6590 & 0.917 & 0.767 & 16.36 & 0.963 & 5.02 & 0.825 & 10.03 \\
\hline & 15,000 & 0.269 & 6489 & 0.903 & 0.731 & 19.05 & 0.949 & 5.09 & 0.808 & 10.52 \\
\hline & 25,000 & 0.448 & 5390 & 0.750 & 0.552 & 26.4 & 0.838 & 11.73 & 0.665 & 11.33 \\
\hline & 35,000 & 0.628 & 4420 & 0.615 & 0.372 & 39.51 & 0.652 & 6.02 & 0.507 & 17.56 \\
\hline & 45,000 & 0.807 & 3054 & 0.425 & 0.193 & 54.59 & 0.385 & 9.41 & 0.320 & 24.71 \\
\hline
\end{tabular}

TABLE 7: Fatigue life under different stress amplitudes.

\begin{tabular}{lcccc}
\hline Level & 1 & 2 & 3 & 4 \\
\hline Stress amplitude/MPa & 224.20 & 246.49 & 359.87 & 503.18 \\
Life/cycle & 719,424 & 312,500 & 12,098 & 524 \\
\hline
\end{tabular}


TABLE 8: The comparison of experimental results and model-predicted results under three-block loading.

\begin{tabular}{|c|c|c|c|c|c|c|c|c|c|c|}
\hline \multirow{2}{*}{ Stress amplitude } & \multicolumn{4}{|c|}{ Experimental } & \multicolumn{2}{|c|}{ Miner } & \multicolumn{2}{|c|}{ Manson } & \multicolumn{2}{|c|}{ Proposed model } \\
\hline & $\mathrm{d} 1$ & $\mathrm{~d} 2$ & Result & $\mathrm{d} 3$ & $\mathrm{~d} 3$ & Dev/\% & d3 & Dev/\% & $\mathrm{d} 3$ & Dev $/ \%$ \\
\hline $\mathrm{S} 1, \mathrm{~S} 3$, and S4 & 0.556 & 0.248 & 327 & 0.646 & 0.196 & 69.7 & 0.986 & 52.6 & 0.688 & 6.53 \\
\hline $\mathrm{S} 1, \mathrm{~S} 4$, and $\mathrm{S} 3$ & 0.556 & 0.191 & 5392 & 0.517 & 0.253 & 51.1 & 0.376 & 27.3 & 0.409 & 20.95 \\
\hline $\mathrm{S} 4, \mathrm{~S} 3$, and S2 & 0.191 & 0.248 & 43431 & 0.159 & 0.561 & 253 & 0.037 & 77.0 & 0.107 & 32.58 \\
\hline $\mathrm{S} 4, \mathrm{~S} 2$, and $\mathrm{S} 3$ & 0.287 & 0.064 & 4001 & 0.334 & 0.649 & 94.3 & 0.100 & 70.0 & 0.357 & 6.80 \\
\hline
\end{tabular}

TABle 9: Applied cycles and failure cycles under different stress amplitudes.

\begin{tabular}{lcccc}
\hline Level & 1 & 2 & 3 & 4 \\
\hline Stress amplitude/MPa & 260 & 275 & 290 & 305 \\
Applied cycle, $n /$ cycle & 210,000 & 110,500 & 60,000 & 33,750 \\
Failure cycle, N/cycle & 840,000 & 442,000 & 240,000 & 135,000 \\
\hline
\end{tabular}

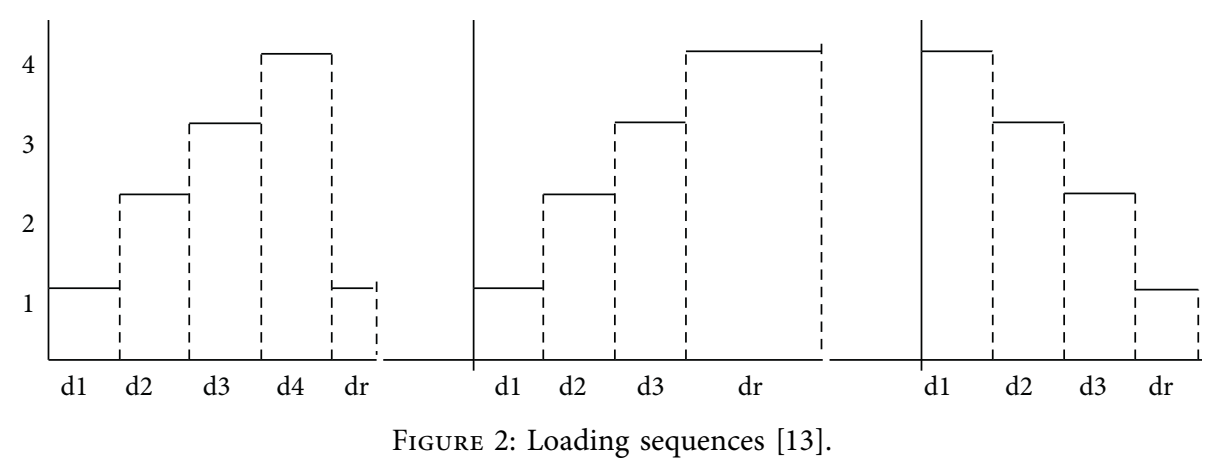

TABLE 10: The comparison of experimental results and model-predicted results under four-block loading.

\begin{tabular}{lccccccccc}
\hline & \multicolumn{3}{c}{ Loading A, 1-2-3-4-1 } & \multicolumn{2}{c}{ Loading B, 1-2-3-4 } & \multicolumn{3}{c}{ Loading B, 4-3-2-1 } \\
& Total cycles & Dev & Total damage & Total cycles & Dev & Total damage & Total cycles & Dev & Total damage \\
\hline Experimental & 531,000 & - & 1.139 & 434,500 & - & 1.151 & 236,500 & - & 0.79 \\
Miner & 414,250 & 21.9 & 1 & 414,250 & 4.70 & 1 & 414,250 & 75.1 & 1 \\
Manson & 522,670 & 1.57 & 1.129 & 447,940 & 3.06 & 1.250 & 266,780 & 7.44 & 0.872 \\
Proposed model & 450,236 & 15.21 & 1.043 & 426,858 & 1.76 & 1.093 & 338,170 & 42.99 & 0.909 \\
\hline
\end{tabular}

When the ratio of second loading to first loading is greater than 1, the remaining fatigue damage tends to increase with the increase of the ratio. Because the fatigue damage is manifested as the collective crack diffusion without interaction under the action of the first-order low stress, when the damage accumulates to a certain extent, the cracks of different types and orientations interact with each other at an increasing rate, forming local stress concentration and causing local damage. Therefore, the local stress concentration is very large under the added high stress, and local failure occurs very quickly.

On the contrary, when the ratio of second loading to first loading is less than 1 , the remaining fatigue damage tends to decrease with the decrease of the ratio. Because the first level of high stress quickly makes the matrix crack saturation and forms local stress concentration, the degree of local stress concentration decreases under the later addition of low stress. Only when the accumulative stress reaches a certain degree will the local damage continue to develop until destruction.
A large number of fatigue crack propagation tests [19-21] show that the actual crack propagation life of specimens under high-low load is generally longer than that calculated by the corresponding theoretical crack propagation model. When the specimen is subjected to low-high load, the actual crack growth life is generally shorter than the corresponding theoretical crack growth life, mainly because the sequence of loads affects the fatigue crack growth rate of the material to a certain extent.

Therefore, it also satisfies the fatigue test law, which shows that cumulative fatigue damage is greater than 1 at low-high loading blocks and is less than 1 at the high-low loading blocks.

4.2. Comparison of Results. We compare the mean deviation, standard deviation, and maximum deviation of cumulative life and damage for models prediction under three kinds of block loading, shown in Tables 11 and 12, respectively. These three statistics of cumulative life are close to each other between the 


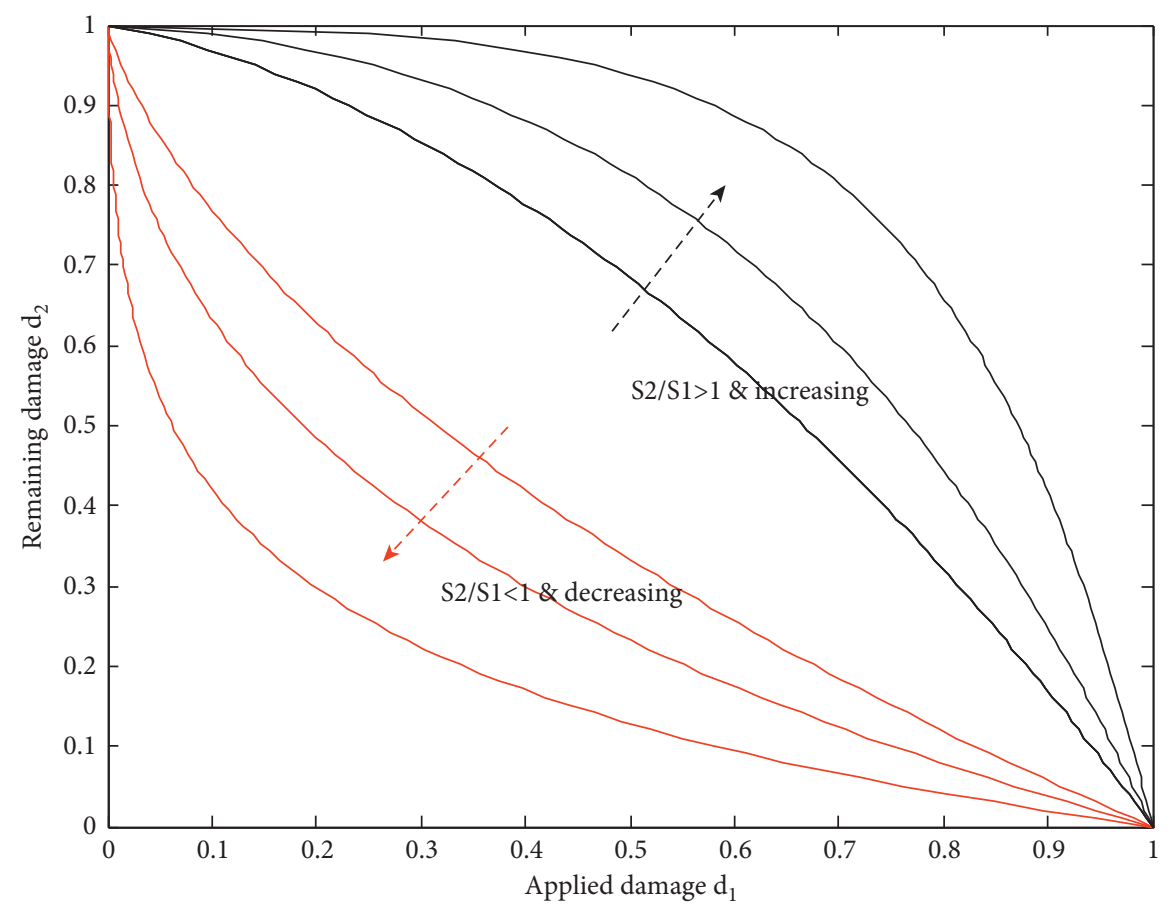

Figure 3: The characteristics of the proposed model in fatigue damage prediction under two-block loading.

TABle 11: Statistical analysis of cumulative life for model prediction under multiblock loading.

\begin{tabular}{lccc}
\hline Statistics parameters & Mean deviation (\%) & Standard deviation & Maximum deviation (\%) \\
\hline Miner & 37.61 & 0.5823 & 283.43 \\
Manson & 39.31 & 0.6400 & 240.46 \\
Proposed model & 13.80 & 0.1497 & 49.29 \\
\hline
\end{tabular}

TABLE 12: Statistical analysis of cumulative damage for model prediction under multiblock loading.

\begin{tabular}{lccc}
\hline Statistics parameters & Mean deviation (\%) & Standard deviation & Maximum deviation (\%) \\
\hline Miner & 24.51 & 0.1410 & 67.22 \\
Manson & 9.17 & 0.0640 & 34.16 \\
Proposed model & 9.94 & 0.0925 & 28.13 \\
\hline
\end{tabular}

Miner model and Manson model and larger than those of the proposed model. These three statistics of cumulative damage are close to each other between the Manson model and proposed model and less than those of the Miner model.

Meanwhile, we summarize the fatigue cumulative life and damage of models in three kinds of block loading and compare with experiments, as shown in Figures 4 and 5, respectively. From Figures 4 and 5, note that nearly all predicted cumulative life of the proposed model fall within \pm 2 life and \pm 0.3 damage of the experimental data under the three kinds of block loading.

Therefore, the proposed model's expectations are in better agreement with experimental results than the Miner model and Manson model with those compared. 


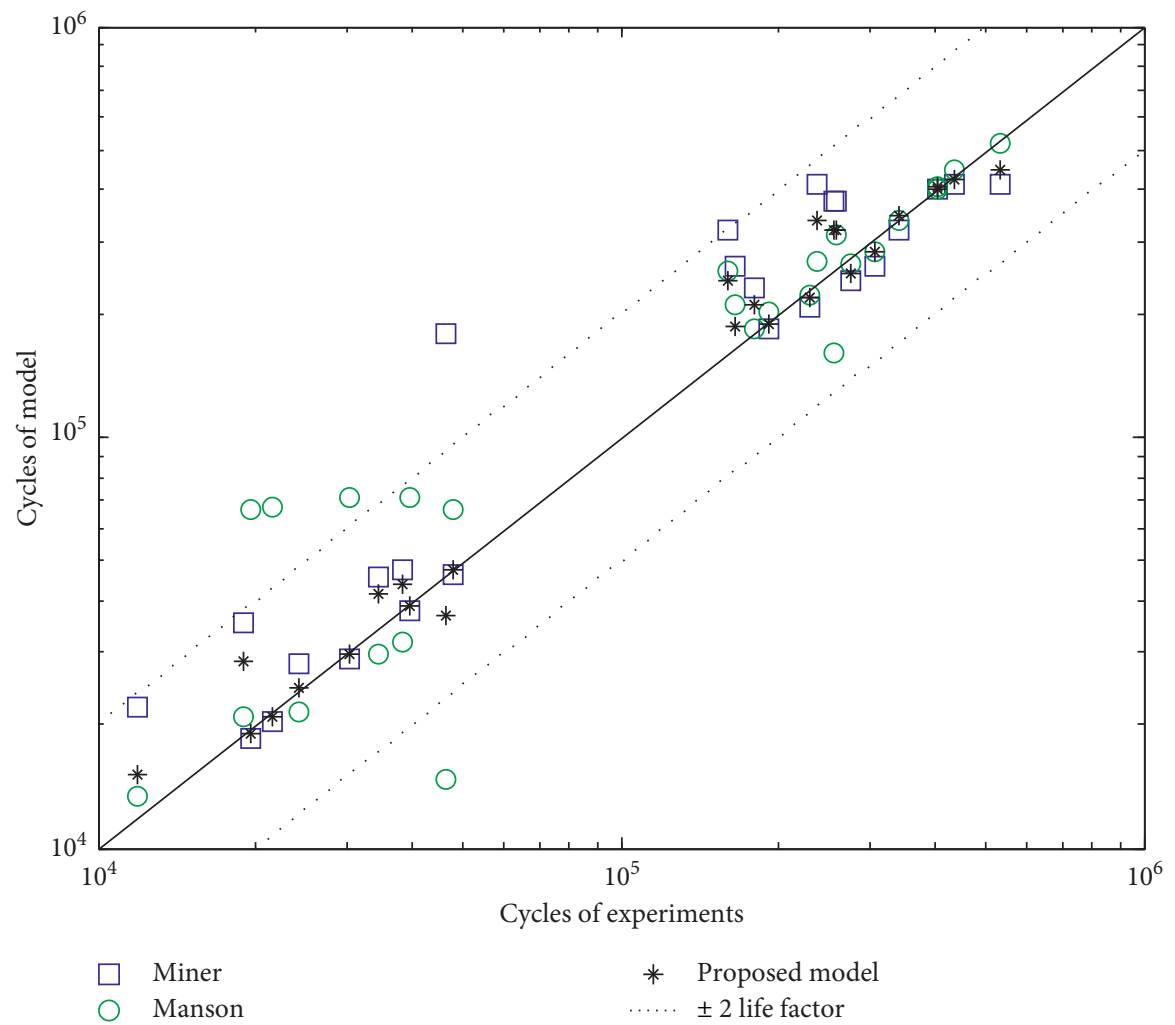

FIgURE 4: Comparison of fatigue cumulative life in three kinds of block loading.

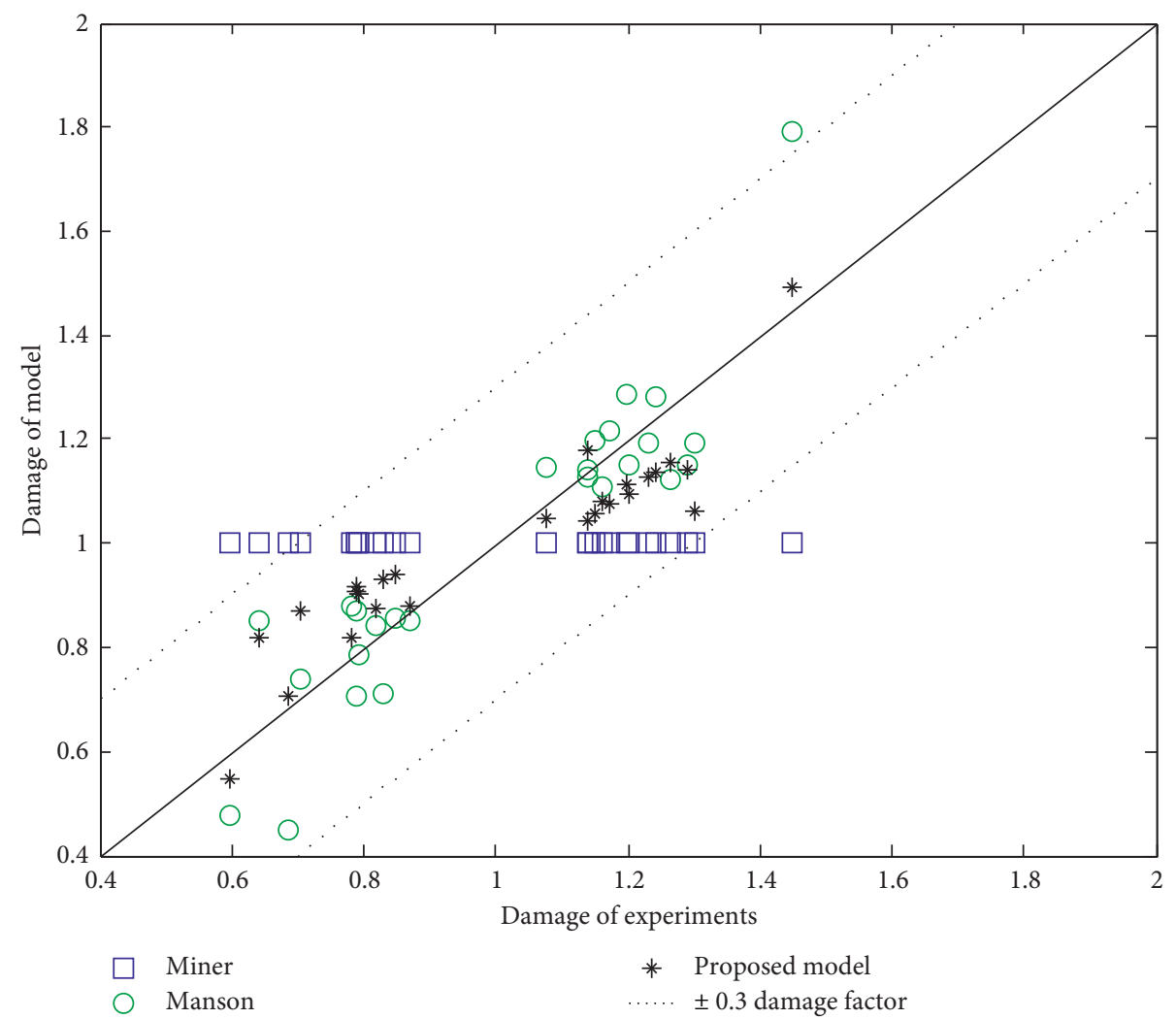

FIGURE 5: Comparison of fatigue cumulative damage in three kinds of block loading. 


\section{Conclusions}

In this paper, we proposed a new nonlinear fatigue damage model based on equivalent transformation of stress that does not need to determine any parameter and just requires the information of the $\mathrm{S}-\mathrm{N}$ curve determined from the fatigue experiments. The proposed model defines a stress equivalent transformation way to translate the damage of one stress to another stress through simple calculation. The proposed method is validated using experimental data which includes two-, three-, and four-block loading. The present model fits the experimental data well for variable amplitude loading, and the algorithm is very simple to be implemented.

\section{Data Availability}

All data generated or analyzed during this study are included in this article. Additional data can be obtained by contacting the corresponding author.

\section{Conflicts of Interest}

The authors declare no conflicts of interest.

\section{Acknowledgments}

The authors gratefully acknowledge the funding support provided by the Central Public-Interest Scientific Institution Basal Research Fund (No. 2019-0115, 2021-9035b), National Key Research and Development Program of China (No. 2020YFC1511904), and Innovation Fund of RIOH (No. 2018-E0031).

\section{References}

[1] M. S. Cheung and W. C. Li, "Probabilistic fatigue and fracture analysis of steel bridges [J]," Journal of Structural Safety, vol. 23, no. 2, pp. 245-262, 2003.

[2] M. A. Miner, "Cumulative damage in fatigue," Journal of Applied Mechanics, vol. 67, no. 3, pp. 157-164, 1945.

[3] R. Antonino and R. Giacomo, "Cumulative damage evaluation in multiple cycle fatigue tests taking into account energy parameters," International Journal of Fatigue, vol. 48, no. 10, pp. 214-222, 2013.

[4] S. S. Manson, J. C. Freche, and C. R. Ensign, "Application of a double linear damage rule to cumulative fatigue," Fatigue Crack Propagation, vol. 415, pp. 384-412, 2012.

[5] S. S. Manson and G. R. Halford, "Practical implementation of the double linear damage rule and damage curve approach for treating cumulative fatigue damage," International Journal of Fracture, vol. 17, no. 2, pp. 169-192, 1981.

[6] S. Subramanyan, "A cumulative damage rule based on the knee point of the S-N curve," Journal of Engineering Materials and Technology, vol. 98, no. 4, pp. 316-321, 1976.

[7] Z. Hashin and A. Rotem, "A cumulative damage theory of fatigue failure," Materials Science and Engineering, vol. 34, no. 2, pp. 147-160, 1978.

[8] D.-G. Shang and W.-X. Yao, "A nonlinear damage cumulative model for uniaxial fatigue[J]," International Journal of Fatigue, vol. 21, pp. 187-194, 1999.
[9] W. X. Yao and N. Himmel, "A new cumulative fatigue damage model for fibre-reinforced plastics," Composites Science and Technology, vol. 60, no. 1, pp. 59-64, 2000.

[10] H. Huang, S. Zhu, and Z. Wang, "Nonlinear fatigue damage cumulative rule based on strength degradation and its application to fatigue life reliability analysis," Journal of Basic Science and Engineering, vol. 19, no. 2, pp. 323-334, 2011.

[11] F. Wu and W. Yao, "A fatigue damage model of composite materials," International Journal of Fatigue, vol. 32, no. 1, pp. 134-138, 2010.

[12] A. Djebli, A. Aid, M. Bendouba, A. Amrouche, M. Benguediab, and N. Benseddiq, "A non-linear energy model of fatigue damage accumulation and its verification for Al-2024 aluminum alloy," International Journal of Non-linear Mechanics, vol. 51, no. 1, pp. 145-151, 2013.

[13] G. Mesmacque, S. Garcia, and A. Amrouche, "Sequential law in multiaxial fatigue: a new damage indicator," International Journal of Fatigue, vol. 27, no. 4, pp. 1-7, 2005.

[14] W. Weibull, Fatigue Testing and Analysis of Results, Pergamon Press, Oxford, England, 1961.

[15] D. G. Pavlou, "A phenomenological fatigue damage accumulation rule based on hardness increasing, for the 2024-T42 aluminum," Engineering Structures, vol. 24, no. 11, pp. 1363-1368, 2002.

[16] A. Aid, A. Amrouche, B. B. Bouiadjra, M. Benguediab, and G. Mesmacque, "Fatigue life prediction under variable loading based on a new damage model," Materials \& Design, vol. 32, no. 1, pp. 183-191, 2011.

[17] Y. Q. Fang, M. M. Hu, and Y. L. Luo, "New continuous fatigue damage model based on whole damage field measurement," Journal of Mechanical Strength, vol. 28, no. 4, pp. 582-586, 2006.

[18] M. Hu, J. Tang, and P. Wei, "S-N curve movement-based life analytical model," Journal of Hohai University: Natural Science, vol. 31, no. 1, pp. 60-63, 2003.

[19] M. Aslam and S. Jeelani, "Prediction of cumulative fatigue damage," Journal of Materials Science, vol. 20, no. 9, pp. 3239-3244, 1985.

[20] V. Dattoma, S. Giancane, R. Nobile, and F. Panella, "Fatigue life prediction under variable loading based on a new nonlinear continuum damage mechanics model," International Journal of Fatigue, vol. 28, no. 2, pp. 89-95, 2006.

[21] F. Taheri, D. Trask, and N. Pegg, "Experimental and analytical investigation of fatigue characteristics of 350WT steel under constant and variable amplitude loadings," Marine Structures, vol. 16, no. 1, pp. 69-91, 2003. 